\title{
Serum of sickle cell disease patients contains fetal hemoglobin silencing factors secreted from leukocytes
}

This article was published in the following Dove Press journal: Journal of Blood Medicine

\author{
Tohru Ikuta' \\ Hassan Sellak' \\ Si-Yang Liu ${ }^{2}$ \\ Nadine Odo' \\ 'Department of Anesthesiology and \\ Perioperative Medicine, Medical \\ College of Georgia, Augusta \\ University, Augusta, GA, USA; \\ ${ }^{2}$ Department of Biochemistry and \\ Molecular Biology, Medical College of \\ Georgia, Augusta University, Augusta, \\ GA, USA
}

Background: The mechanisms that regulate fetal hemoglobin ( $\mathrm{HbF})$ expression in sickle cell disease (SCD) remain elusive. We previously showed that steady-state SCD patients with high $\mathrm{HbF}$ levels due to a $\gamma$-globin gene mutation demonstrate strong inverse correlations between $\mathrm{HbF}$ levels and leukocyte counts, suggesting that leukocytes play a role in regulating HbF in SCD.

Materials and methods: To further investigate the role of leukocytes in HbF expression in $\mathrm{SCD}$, we examined the presence of $\mathrm{HbF}$ silencing factors in the serum of $82 \mathrm{SCD}$ patients who received hydroxyurea (HU) therapy.

Results: $\mathrm{HU}$-mediated $\mathrm{HbF}$ induction was associated with elevated total hemoglobin levels and improved red blood cell parameters, but there was no correlation with reticulocyte or platelet counts. Importantly, we again found that HU-induced HbF levels correlated with reductions in both neutrophils and lymphocytes/monocytes, indicating that these cell lineages may have a role in regulating $\mathrm{HU}$-mediated $\mathrm{HbF}$ expression. Our in vitro studies using $\mathrm{CD} 34^{+}$-derived primary erythroblasts found that patient serum preparations include $\mathrm{HbF}$ silencing factors that are distinct from granulocyte-macrophage colony-stimulating factor, and the activity of such factors decreases upon HU therapy.

Conclusion: Together, these results demonstrate the importance of leukocyte numbers in the regulation of $\mathrm{HbF}$ levels for SCD patients both in steady state and under HU therapy, and that leukocytes secrete $\mathrm{HbF}$ silencing factors that negatively affect $\mathrm{HbF}$ expression in erythroidlineage cells in SCD.

Keywords: sickle cell disease, leukocytes, hydroxyurea, fetal hemoglobin, silencing factors

\section{Introduction}

The primary genetic defect in sickle cell disease (SCD) is a mutation of the $\beta$-globin gene. ${ }^{1}$ It produces sickle hemoglobin, which polymerizes under low oxygen tension. This formation of sickle hemoglobin polymers is assumed to underlie vaso-occlusive crisis, chronic hemolysis, and ischemia-reperfusion injury associated with inflammation in this disorder. ${ }^{2-4}$

Despite sharing a common $\beta$-globin mutation, the clinical severity among patients with SCD is extremely heterogeneous and the underlying mechanisms remain unknown. Elevated levels of fetal hemoglobin $(\mathrm{HbF})$ expression alleviate the clinical severity of $\mathrm{SCD}$; however, expression levels are also variable. ${ }^{5} \mathrm{HbF}$ expression is regulated by single-nucleotide polymorphisms (SNPs) of multiple genetic loci, ${ }^{6-8}$ which presumably help to determine the level of $\mathrm{HbF}$ production in SCD. ${ }^{9}$ In addition to $\mathrm{HbF}$, which is otherwise dormant in people without anemia, leukocytosis is frequently observed in untreated SCD patients even in the absence of bacterial infection. ${ }^{10}$ An elevated baseline
Department of Anesthesiology and Perioperative Medicine, Medical College of Georgia, Augusta University, I 120 15th Street, BIW-2144, Augusta, GA 30912, USA

Tel + I 7067213098

Fax +I 70672 I 8752

Email tikuta@augusta.edu 
leukocyte count is associated with a risk for early death. ${ }^{11}$ Further, high leukocyte counts in children with SCD predict severe clinical complications later in life. ${ }^{12}$ These clinical observations suggest that both $\mathrm{HbF}$ levels and leukocyte counts are consequential to the clinical severity of SCD.

Although the pharmacological stimulation of $\mathrm{HbF}$ expression by hydroxyurea (HU) is an established treatment for patients with clinically severe $\mathrm{SCD},{ }^{13} \mathrm{HbF}$ response to $\mathrm{HU}$ varies significantly and a number of SCD patients are resistant to $\mathrm{HU}$ therapy. Clarifying the predictors of $\mathrm{HbF}$ response to HU will allow clinicians to determine which patients are most likely to respond to HU therapy. This will in turn limit the toxicities associated with the treatment among those who would not benefit from the therapy. A study by Charache et al showed that initial leukocyte count and $\mathrm{HbF}$ concentration as well as post-therapy plasma $\mathrm{HU}$ levels are predictors of high post-therapy HbF levels. ${ }^{14}$ Ware et al also demonstrated that greater changes in blood counts in SCD children on HU therapy result in better $\mathrm{HbF}$ response to HU. ${ }^{15}$ However, the mechanisms by which these hematologic parameters predict $\mathrm{HbF}$ response remain elusive.

As to the mechanisms responsible for leukocytosis in SCD, we had reported a positive correlation between leukocyte count and plasma granulocyte-macrophage colonystimulating factor (GM-CSF) levels in SCD patients, ${ }^{16}$ indicating that plasma GM-CSF levels help to regulate leukocyte count. We subsequently analyzed retrospective data from SCD patients receiving HU therapy and found that the rate of $\mathrm{HbF}$ induction associated with $\mathrm{HU}$ therapy is proportional to the reduction of peripheral blood leukocyte count. ${ }^{17}$ We also found that GM-CSF has a negative regulatory effect on $\mathrm{HbF}$ expression. ${ }^{17}$ These results suggest that leukocytes are an important regulator for determining $\mathrm{HbF}$ response to HU.

To determine whether leukocytes are also involved in the regulation of $\mathrm{HU}-$ mediated $\mathrm{HbF}$ expression in $\mathrm{SCD}$, in this study we analyzed retrospectively collected pre-HU and postHU therapy hematological data. We found that $\mathrm{HbF}$ response was again associated with reduced leukocyte count, but not reticulocyte and platelet counts, suggesting that leukocytes likely play a critical role in $\mathrm{HbF}$ response to HU. Furthermore, our in vitro studies suggest that patient sera contain as-yet unidentified factors that appear to inhibit $\mathrm{HbF}$ expression in $\mathrm{CD} 4^{+}$-derived erythroid progenitors cultured with erythropoietin (Epo). Interestingly, the ability to inhibit HbF activity varied among steady-state patients and was significantly decreased upon HU therapy. This study has revealed novel aspects of the molecular mechanisms by which HU regulates
$\mathrm{HbF}$ expression, which will help us to better understand $\mathrm{HU}$ resistance among SCD patients..$^{15,18}$

\section{Materials and methods SCD patient blood serum}

The study was performed in accordance with the principles of the Declaration of Helsinki and approved by the institutional review board of Augusta University. We collected retrospective data on 337 adult SCD patients who were homozygous for the $\beta^{s}$ mutation and under the care of the Sickle Cell Center of the Medical College of Georgia at Augusta University; the clinical characteristics of this cohort were reported previously. ${ }^{17}$ Of these patients, 82 were receiving HU therapy (15-35 mg/kg/day) and had not received transfusions for at least 6 months. Hematologic values were reported as the average of at least 3 months of data. Serum preparations that had no visible hemolysis were obtained from multiple patients under HU therapy, before daily intake of HU to minimize carryover of HU. Written informed consent was obtained from all patients.

\section{In vitro culture of human CD34+-derived erythroid progenitor cells}

Human CD34 ${ }^{+}$cells obtained from the National Heart, Lung and Blood Institute Programs of Excellence in Gene Therapy Hematopoietic Cell Processing Core (Fred Hutchinson Cancer Research Center, Seattle, WA, USA) were cultured by a method described previously ${ }^{19}$ with minor modifications. Briefly, CD34 ${ }^{+}$cells $\left(1-10 \times 10^{4}\right.$ cells $\left./ \mathrm{mL}\right)$ were cultured in Iscove's modified Dulbecco's medium containing 30\% fetal bovine serum (FBS) or $30 \%$ human $\mathrm{AB}$ serum, 3 unit $/ \mathrm{mL}$ Epo, $20 \mathrm{ng} / \mathrm{mL}$ stem cell factor, and $10 \mathrm{ng} / \mathrm{mL}$ interleukin 3. Culture media were replaced every 4 days. Anti-human GMCSF antibody (Thermo Fisher Scientific, Waltham, MA, USA) was added to sera from SCD patients at a dilution ratio of $1: 10$ followed by a 30 -minute incubation at room temperature before adding to culture media. Cells were harvested on day 14. Cell photographs were taken by EVOS FL Cell Imaging System (Advanced Microscopy Group, Bothell, WA, USA).

\section{Flow cytometry}

Cells were suspended in FACS buffer (phosphate-buffered saline containing $5 \% \mathrm{FBS}$ and $0.1 \%$ sodium azide). Following incubation with human Fc blocker (Thermo Fisher Scientific) for 10 minutes at room temperature, cells were then washed twice in FACS buffer and stained at $4^{\circ} \mathrm{C}$ for 30 minutes with a phycoerythrin (PE)-labeled anti-human glycophorin A monoclonal antibody (CD235a PE) (BD Biosciences, San 
Jose, CA, USA) and fluorescein isothiocyanate-labeled CD71 monoclonal antibody (BD Biosciences). Paraformaldehyde was added in an equal volume to a final concentration of $0.1 \%$ to fix cells for 30 minutes at room temperature. The expression of glycophorin A and CD71 on erythroblasts was analyzed in a Becton-Dickinson FACScan using Cell Quest software (Franklin Lakes, NJ, USA). ${ }^{20}$ Data were represented as percent of positive cells.

\section{Isolation of whole cell extracts from erythroblasts and immunoblotting}

Whole cellular extracts were prepared from $\mathrm{CD}_{3} 4^{+}$-derived erythroblasts as described. ${ }^{21}$ Briefly, cells $\left(5-10 \times 10^{6}\right.$ cells $)$ were suspended with $1 \times$ RIPA lysis buffer (Santa Cruz Biotechnology, Santa Cruz, CA, USA) supplemented with $1 \mathrm{mM}$ phenyl-methyl sulfonyl fluoride, $100 \mathrm{mM}$ sodium orthovanadate, and protease inhibitor cocktail. Whole cellular extracts were obtained by centrifugation at $14,000 \times g$ for 15 minutes. Immunoblotting was performed as described previously. ${ }^{22}$ Approximately 2-3 micrograms of cellular extracts were separated on $12 \%$ SDS polyacrylamide gels and transferred to nitrocellulose membranes (Invitrogen, Carlsbad, CA, USA). All antibodies used for immunoblotting analyses were purchased from Santa Cruz Biotechnology unless otherwise stated. Protein bands were visualized by the Phototope HRP Western blot detection system (Cell Signaling Technology, Danvers, MA, USA) according to the protocol provided by the supplier. Immunoblotting for $\gamma$-globin expression was performed by using serum preparations with no visible hemolysis that were isolated from multiple SCD patients.

\section{Real-time (RT)-PCR}

Expression of $\gamma$-globin mRNA in human $\mathrm{CD} 34^{+}$-derived erythroid progenitors treated with or without SCD patients' serum was examined by RT-PCR as described previously. ${ }^{23}$ To determine expression levels of human $\gamma$-globin mRNA in primary erythroblasts, human $\mathrm{CD} 34^{+}$cells were cultured as described above. Total RNA was extracted from primary erythroblasts using RNeasy Mini Kit (Qiagen, Germantown, MD, USA), and cDNA was generated with the SuperScript II Reverse Transcriptase kit (Invitrogen). RT-PCR was carried out with the Mx3000P QPCR System (Agilent Technologies, Santa Clara, CA, USA) using SYBR Green Supermix (Bio-Rad, Hercules, CA, USA) according to the manufacturer's instructions. All amplifications were performed in triplicate, and 18S rRNA was used as internal control. Relative expression was quantitated using the standard $\Delta \Delta \mathrm{Ct}$ method. The primers used were as follows: human $\gamma$-globin,
forward-5'-TGGATGATCTCAAGGGCAAC-3'; reverse5'-TCAGTGGTATCTGGACA-3'; human 18S rRNA, forward-5'-TTGGAGGGCAAGTCTGGTG-3'; reverse5'- CCGCTCCCAAGATCCAACTA-3'. All primers were designed and obtained from Integrated DNA Technologies (Coralville, IA, USA). RT-PCR for $\gamma$-globin mRNA expression was carried out by using several serum preparations with no visible hemolysis from multiple SCD patients.

\section{Statistical analysis}

The Spearman correlation coefficient $\left(r_{\mathrm{s}}\right)$ was used for correlations with non-Gaussian distributed data, which included hematologic values (Figures 1-4). Other data were analyzed by Student's $t$-test. $P$-values less than 0.05 were considered statistically significant.

\section{Results}

\section{Response of $\mathrm{HbF}$ to $\mathrm{HU}$ is associated with hematologic improvements in SCD patients}

Our previous study showed that reduced leukocyte counts in response to HU therapy is critical for efficient HU-mediated $\mathrm{HbF}$ induction. ${ }^{17}$ To further investigate the mechanisms by which $\mathrm{HbF}$ response is regulated in SCD, we first examined whether $\mathrm{HbF}$ response was associated with hematologic improvements in a retrospective study of a cohort of SCD patients described previously. ${ }^{17}$ Of these, $82 \mathrm{HU}$ responders were selected. There were substantial correlations between the levels of $\mathrm{HbF}$ induction by $\mathrm{HU}$ and increases in the total hemoglobin levels, MCV, and MCHC (Figure 1A-C). This suggests that HU therapy significantly improves RBC parameters, suggesting its clinical effectiveness for SCD. Our cohort of SCD patients may be pathophysiologically comparable to those reviewed recently. ${ }^{24}$

\section{$\mathrm{HU}$-induced $\mathrm{HbF}$ levels are not correlated with reticulocyte or platelet counts}

Next, we investigated whether HU-mediated HbF levels correlated with reticulocyte and platelet counts, both of which are assumed to play a role in modulating the pathophysiology of SCD. ${ }^{25,26}$ However, we saw no significant correlations between $\mathrm{HU}$-induced $\mathrm{HbF}$ levels and reticulocyte or platelet counts (Figure 2A and B), suggesting that the mechanisms controlling the numbers of these lineage cells in peripheral blood may not be relevant to the mechanisms by which $\mathrm{HbF}$ response is regulated by $\mathrm{HU}$. 
A

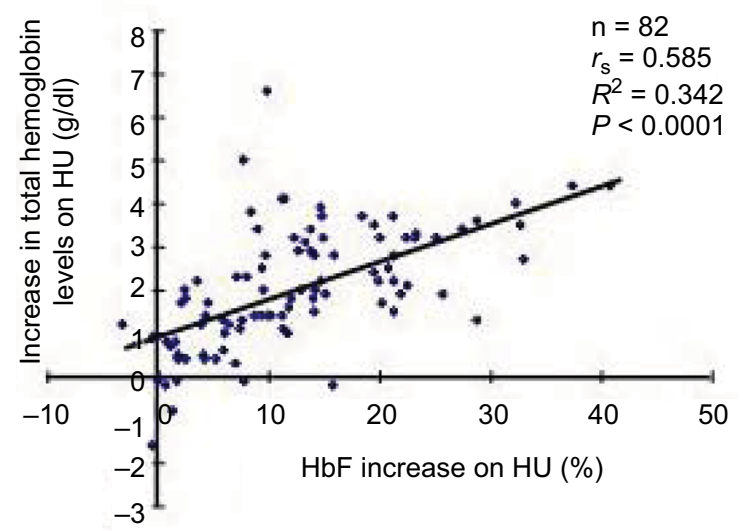

B

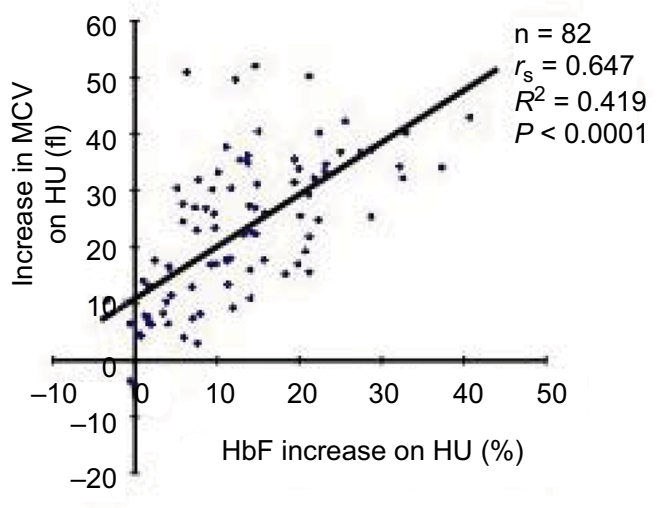

C

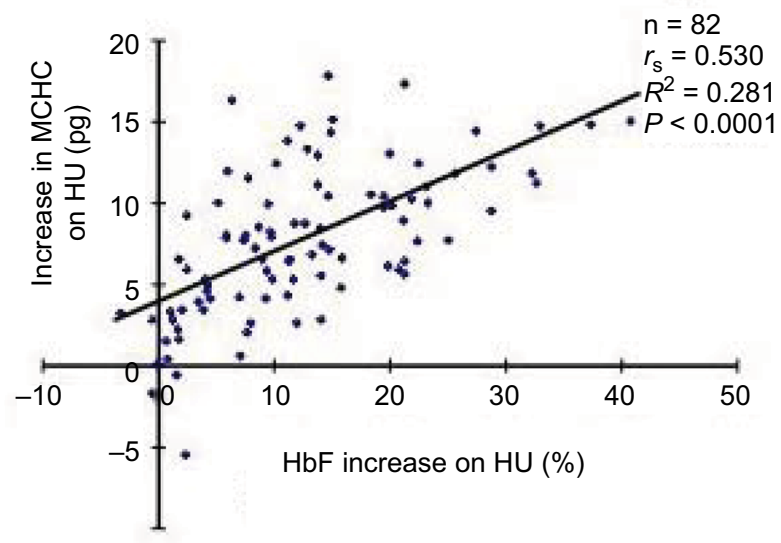

Figure I HbF response to $\mathrm{HU}$ is associated with hematological improvements in SCD patients.

Notes: Increases in HbF levels after HU therapy correlate with increases in total hemoglobin levels (A), MCV (B), and MCHC (C). Correlations were analyzed with 82 SCD patients who received HU therapy.

Abbreviations: $\mathrm{HbF}$, fetal hemoglobin; HU, hydroxyurea; $\mathrm{SCD}$, sickle cell disease.

A

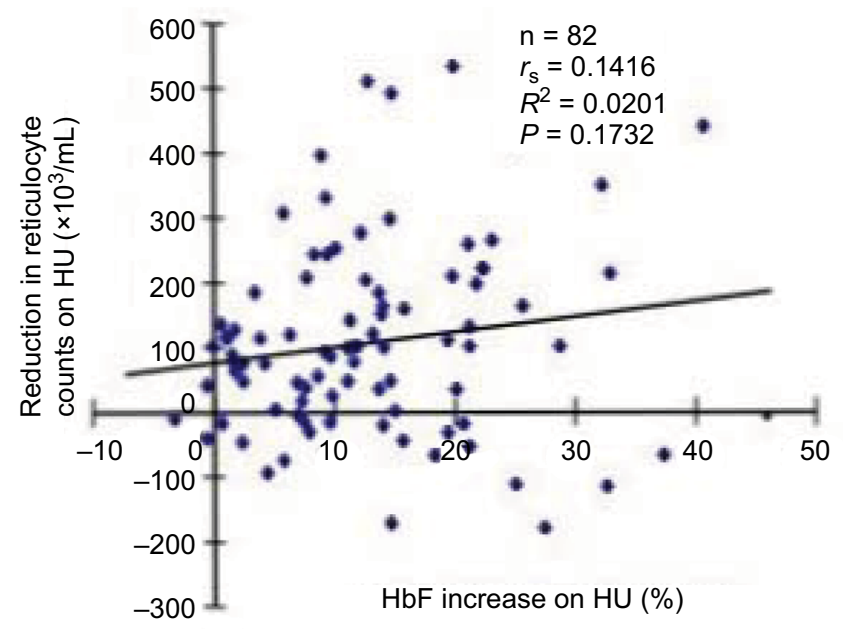

B

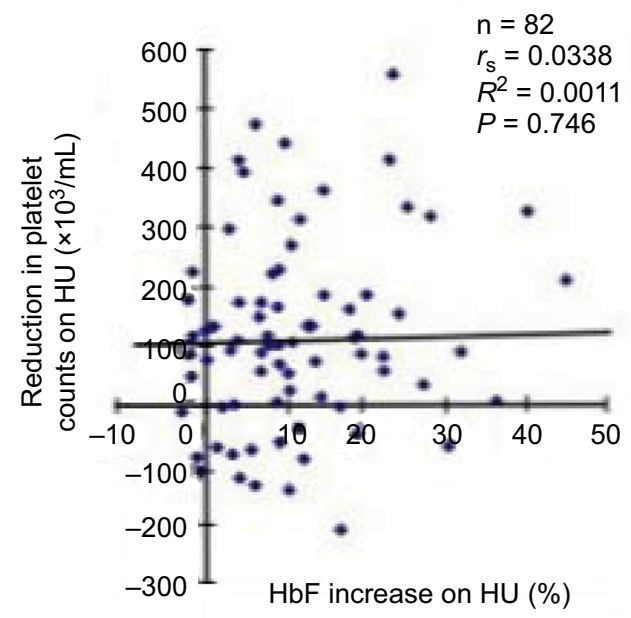

Figure 2 There were no correlations between $\mathrm{HU}$-induced $\mathrm{HbF}$ increases and reductions in the number of reticulocytes $(\mathbf{A})$ and platelets $(\mathbf{B})$ among the SCD patients who received $\mathrm{HU}$ therapy.

Abbreviations: $\mathrm{HU}$, hydroxyurea; HbF, fetal hemoglobin; SCD, sickle cell disease. 
A

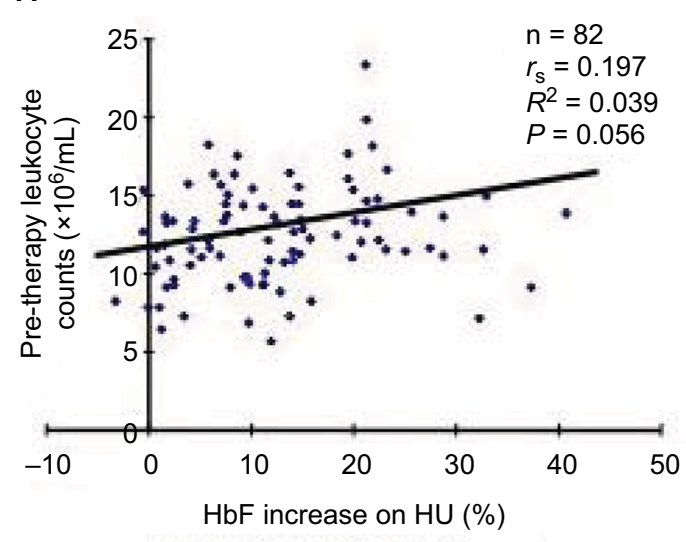

B

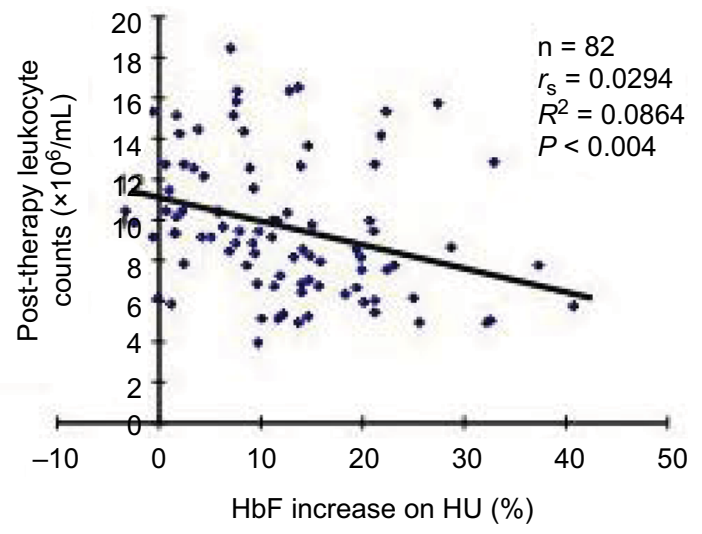

C
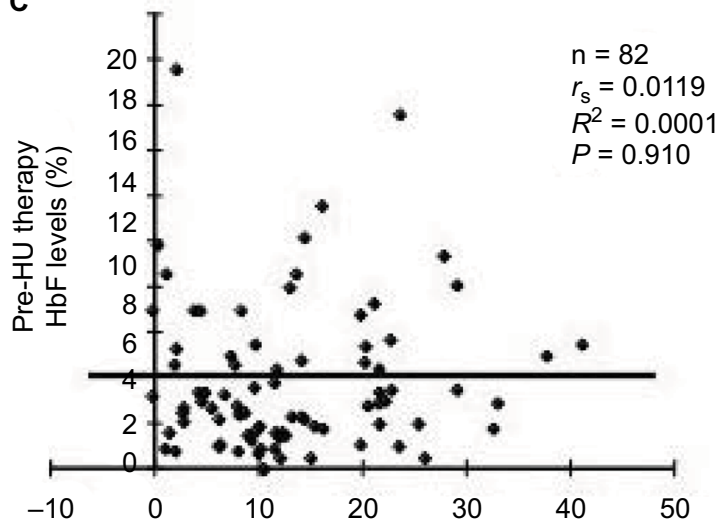

$\mathrm{HbF}$ increase on $\mathrm{HU}(\%)$

Figure 3 Correlations between the levels of HbF increases upon $\mathrm{HU}$ therapy and pre-HU therapy leukocyte counts (A), post-HU therapy leukocyte counts (B), or pre-HU therapy HbF levels (C). Eighty-two SCD patients who received HU therapy were analyzed.

Abbreviations: $\mathrm{HU}$, hydroxyurea; $\mathrm{HbF}$, fetal hemoglobin; $\mathrm{SCD}$, sickle cell disease.

A

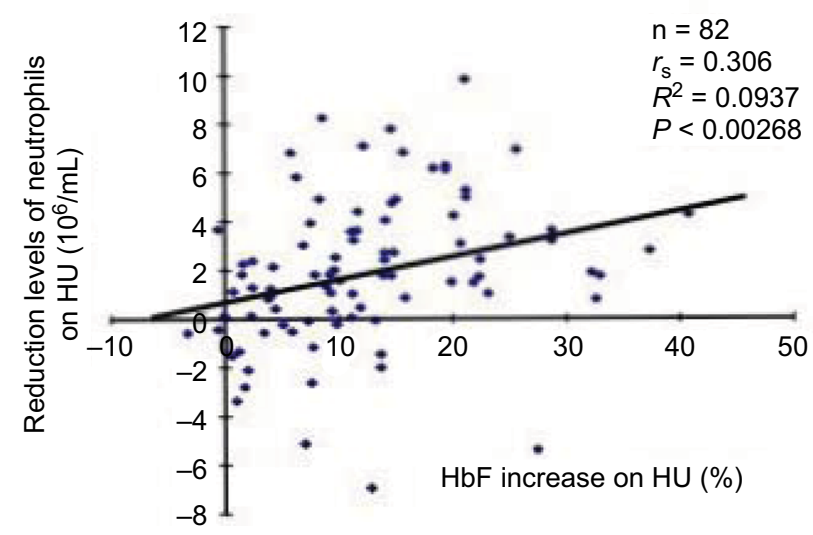

B

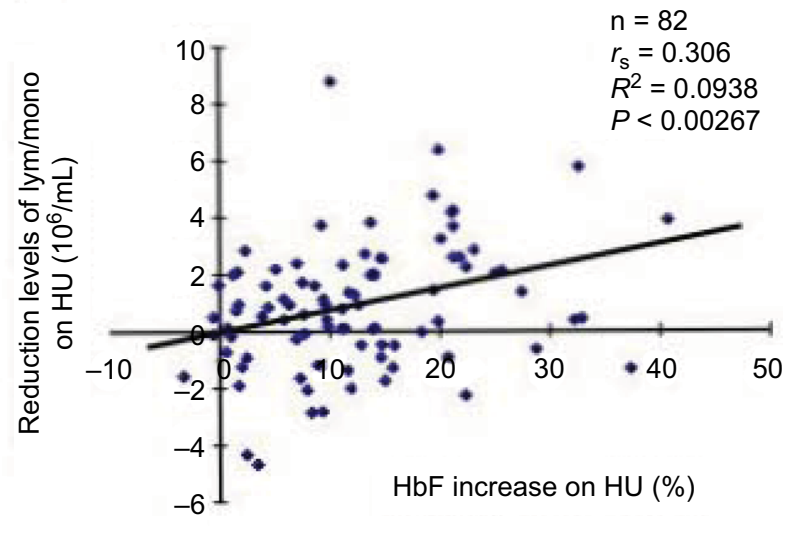

Figure 4 Correlations between neutrophil (A) or lymphocyte/monocyte counts (B) and HU-induced HbF levels. Note: Eighty-two SCD patients who received HU therapy were analyzed.

Abbreviations: $\mathrm{HU}$, hydroxyurea; $\mathrm{HbF}$, fetal hemoglobin; $\mathrm{SCD}$, sickle cell disease. 


\section{Associations between $\mathrm{HU}$-induced $\mathrm{HbF}$ levels and leukocyte counts}

We had previously found that $\mathrm{HU}$-induced $\mathrm{HbF}$ correlates with reduced leukocyte counts, ${ }^{17}$ suggesting that the mechanisms by which $\mathrm{HU}$ regulates $\mathrm{HbF}$ induction in SCD may be relevant to those controlling leukocyte numbers in peripheral blood. Charache et al demonstrated that predictors of $\mathrm{HbF}$ response include pre-therapy leukocyte counts and $\mathrm{HbF}$ levels. ${ }^{14}$ However, we found that HU-mediated $\mathrm{HbF}$ induction levels did not correlate with pre-therapy leukocyte counts (Figure $3 \mathrm{~A}, P=0.056$ ) but did correlate with post-therapy leukocyte counts (Figure 3B, $P<0.004$ ). The $\mathrm{HbF}$ increase was not influenced by pre-therapy $\mathrm{HbF}$ levels (Figure 3C, NS), a result that was inconsistent with Charache et al's study. ${ }^{14}$ This might reflect genetic and cellular differences in the cohorts studied.

To investigate the cell lineages of leukocytes involved in determining $\mathrm{HbF}$ response to HU therapy, we compared HU-mediated $\mathrm{HbF}$ increases and reductions of neutrophil or lymphocyte/monocyte counts (Figure 4). The correlation value between the $\mathrm{HbF}$ increases and the reduction levels of neutrophil counts $(P<0.00268)$ was the almost the same as that between the $\mathrm{HbF}$ increases and lymphocyte/monocyte reductions ( $P<0.00267$; Figure $4 \mathrm{~A}$ and $\mathrm{B})$. This suggests that both cell lineages are involved in determining $\mathrm{HbF}$ levels induced by HU.

\section{$\mathrm{HbF}$ silencing factors that are present in blood serum of SCD patients}

Importantly, the results shown in Figure 5, together with our previous finding that leukocyte counts of steady-state SCD patients with high $\mathrm{HbF}$ levels demonstrated a strong inversely correlation with $\mathrm{HbF}$ levels $\left(\mathrm{N}=47, R^{2}=0.229, P<0,0006\right){ }^{17}$ has led us to hypothesize that leukocytes may have a role in downregulating $\mathrm{HbF}$ expression in erythroid-lineage cells by secreting $\mathrm{HbF}$ silencing factors.

To detect the $\mathrm{HbF}$ silencing factors present in serum of SCD patients, we first determined whether $\mathrm{CD} 34^{+}$cells cultured with $30 \%$ human $\mathrm{AB}$ serum can be differentiated to erythroblasts as our previous studies had employed both FBS and human $\mathrm{AB}$ serum. ${ }^{19,20,27}$ As shown in Figure 5A and $\mathrm{B}$, $30 \%$ human $\mathrm{AB}$ serum permitted $\mathrm{CD} 34^{+}$cells to differentiate to erythroid-lineage cells to a degree similar to that by $30 \%$ FBS, as analyzed by flow cytometry on the basis of expression of glycophorin A and CD71. Next, we investigated the expression of both $\gamma$-globin and $\gamma$-globin mRNA in CD34+-derived erythroblasts incubated with FBS, normal human $\mathrm{AB}$ serum, or SCD patient serum (Figure 5C and D). The leukocyte counts of SCD patients studied here were as follows: Pt.1,

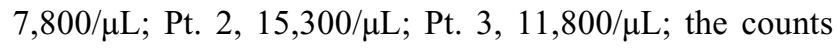
represent average numbers for 3-6 months. Although CD34+derived erythroblasts (lane 2) cultured with $30 \%$ human $\mathrm{AB}$ serum expressed $\gamma$-globin at a level similar to that of cells cultured with $30 \%$ FBS (lane 1), the cells that were cultured with the serum of SCD patients demonstrated significantly lower levels of $\gamma$-globin expression (lanes 3-6). It is of note that the levels of $\gamma$-globin expression was substantially varied among steady-state SCD patients without HU (lanes 3 and 4), and serum from a SCD patient who was receiving HU revealed a weaker $\mathrm{HbF}$ silencing effect (lane 5). Because we previously showed that the proinflammatory cytokine GMCSF has an inhibitory effect on $\mathrm{HbF}$ expression in erythroidlineage cells, ${ }^{17}$ it is confirmed that such $\mathrm{HbF}$ silencing is not blocked by the addition of anti-GM-CSF antibody (lane 6), indicating that $\mathrm{HbF}$ silencing factors are distinct from GMCSF. Next, we examined $\gamma$-globin mRNA expression levels in these erythroblast preparations by RT-PCR (Figure 5D). The results of $\gamma$-globin mRNA expression were in accord with those of immunoblotting shown in Figure 5C. Thus, it is likely that in $\mathrm{SCD}$, leukocytes may secrete $\mathrm{HbF}$ silencing factors that negatively affect $\mathrm{HbF}$ expression in erythroid cells, and that HU may reduce the serum levels of such factors, which may be relevant to $\mathrm{HU}$-mediated $\mathrm{HbF}$ induction in SCD patients.

\section{Discussion}

It is of paramount importance to elucidate the mechanisms by which $\mathrm{HU}$ regulates $\mathrm{HbF}$ expression in the context of SCD because the magnitude of $\mathrm{HbF}$ response to $\mathrm{HU}$ in SCD is remarkably heterogeneous and a large subset of patients are non-responders. ${ }^{28}$ Furthermore, $\mathrm{HU}$-induced $\mathrm{HbF}$ increases are eventually lost even in SCD patients who initially responded to $\mathrm{HU}$ and these underlying mechanisms also remain unknown. ${ }^{15,18} \mathrm{~A}$ number of SNPs associated with $\mathrm{HbF}$ responders in SCD patients have been identified ${ }^{29}$ however, the significance and the implications of such SNPs are yet to be established.

We recently reported that $\mathrm{HU}$-induced $\mathrm{HbF}$ levels correlate with reduced leukocyte counts. ${ }^{17}$ This suggests that the mechanisms mediating $\mathrm{HU}$-induced $\mathrm{HbF}$ expression may be relevant to those that control leukocyte counts. In this study, we performed a retrospective analysis of SCD patients for whom clinical data of pre-HU and post-HU therapy were available. We found that the levels of $\mathrm{HbF}$ induction following HU therapy are associated with the improvements of hematological parameters such as total hemoglobin, MCV, 
A

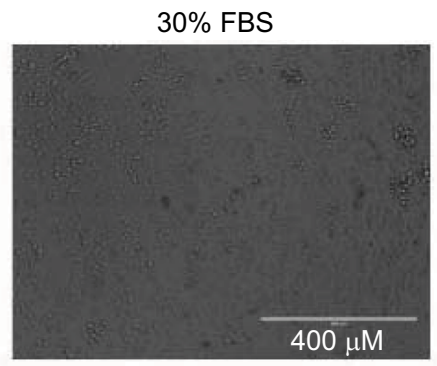

B

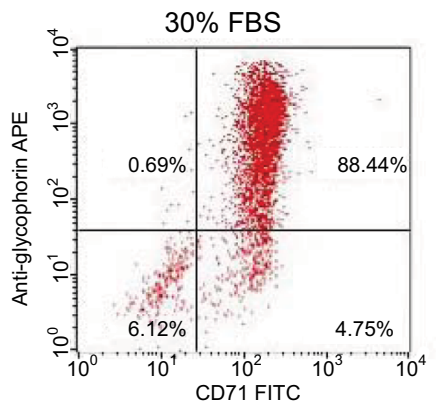

C

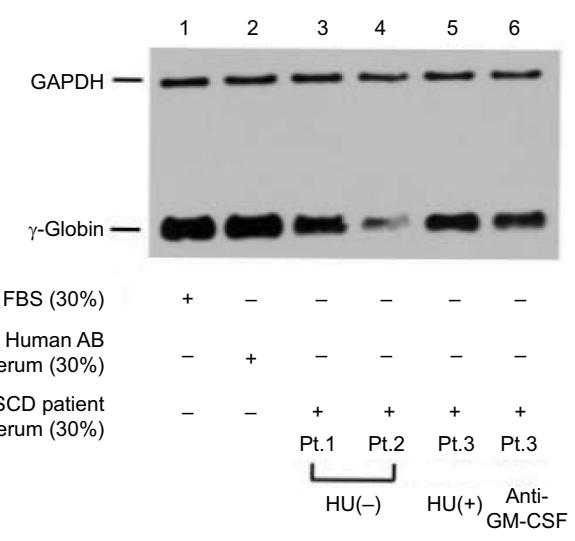

$30 \%$ human $A B$ serum
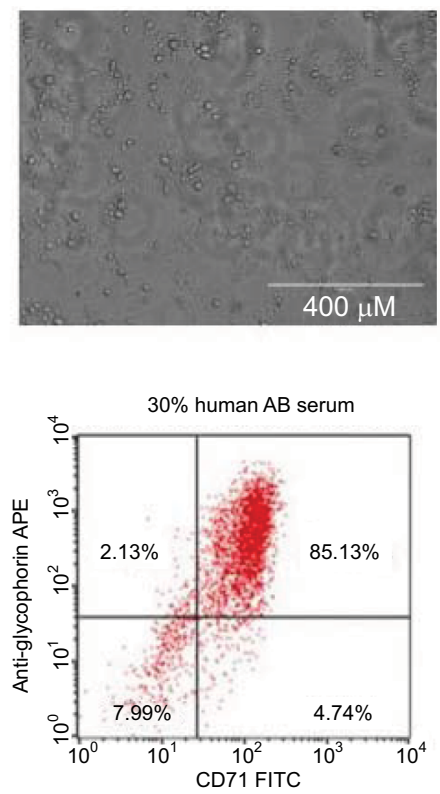

D

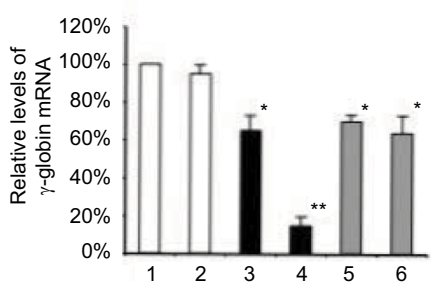

Figure 5 Presence of $\mathrm{HbF}$ silencing factors in serum of SCD patients.

Notes: (A) Culture of CD34+-derived erythroblasts with $30 \%$ FBS (left panel) or $30 \%$ human AB serum (right panel). Cell photographs were taken on day I0 using EVOS FL Cell Imaging System. White bars indicate $400 \mu \mathrm{M}$. (B) Analysis of CD34+-derived erythroblasts that were harvested on day 14 by flow cytometry using anti-glycophorin A and anti-CD7I antibodies. (C) Immunoblotting analysis of $\gamma$-globin and GAPDH in whole cell lysates prepared from CD34 ${ }^{+}$-derived erythroblasts. Lanes: I, CD34 -derived erythroblasts cultured with $30 \%$ FBS; 2 , CD34+-derived erythroblasts cultured with $30 \%$ human $A B$ serum; 3 and 4 , CD $34^{+}$-derived erythroblasts cultured with $30 \%$ serum from steady-state SCD patients (Pt.I and 2); 5, CD34+-derived erythroblasts cultured with $30 \%$ serum from SCD patients with HU therapy; 6, CD34+-derived erythroblasts cultured with $30 \%$ serum from SCD patients with HU therapy that was incubated with anti-GM-CSF antibody as stated in Materials and methods. GAPDH was used for internal control. (D) Quantitation of $\gamma$-globin mRNA levels in CD34+-derived erythroblasts cultured in (C) by RT-PCR. Lane designation is the same as that of (C). The $\gamma$-globin mRNA level of $C D 34^{+}$-derived erythroblasts cultured with $30 \% \mathrm{FBS}$ was set to $100 \%{ }^{*} P<0.05$ compared to lane $\mathrm{I}$. $* * P<0.0 \mathrm{I}$ compared to lane $\mathrm{I}$.

Abbreviations: HbF, fetal hemoglobin; SCD, sickle cell disease; FBS, fetal bovine serum; GAPDH, glyceraldehyde 3-phosphate dehydrogenase; HU, hydroxyurea; GM-CSF, granulocyte-macrophage colony-stimulating factor; RT-PCR, real-time PCR.

and $\mathrm{MCHC}$ (Figure 1), suggesting that $\mathrm{HbF}$ response to $\mathrm{HU}$ is a legitimate marker for confirming the clinical effectiveness of HU therapy. By contrast, there were no significant correlations between $\mathrm{HU}$-induced $\mathrm{HbF}$ levels and reticulocyte or platelet counts (Figure 2), suggesting that these lineage cells are unlikely to play a role in determining $\mathrm{HbF}$ response to $\mathrm{HU}$; rather, their changes reflect secondary effects of HU therapy.

Previous studies have shown correlations between HUinduced $\mathrm{HbF}$ expression and leukocyte counts. ${ }^{15,17,30}$ We also found that $\mathrm{HbF}$ expression levels of steady-state SCD patients with high $\mathrm{HbF}$ levels due to a mutation in the $\mathrm{G} \gamma$-globin gene promoter inversely correlate with leukocyte counts. ${ }^{17}$ Also, a notion that $\mathrm{HU}$-induced $\mathrm{HbF}$ expression may be relevant to the mechanisms controlling leukocyte counts is supported by an earlier report by Steinberg that SCD patients with high baseline leukocyte counts who exhibit a great reduction in leukocytes with HU therapy have more robust increases in $\mathrm{HbF}^{31}$ Thus, multiple lines of clinical evidence strongly 


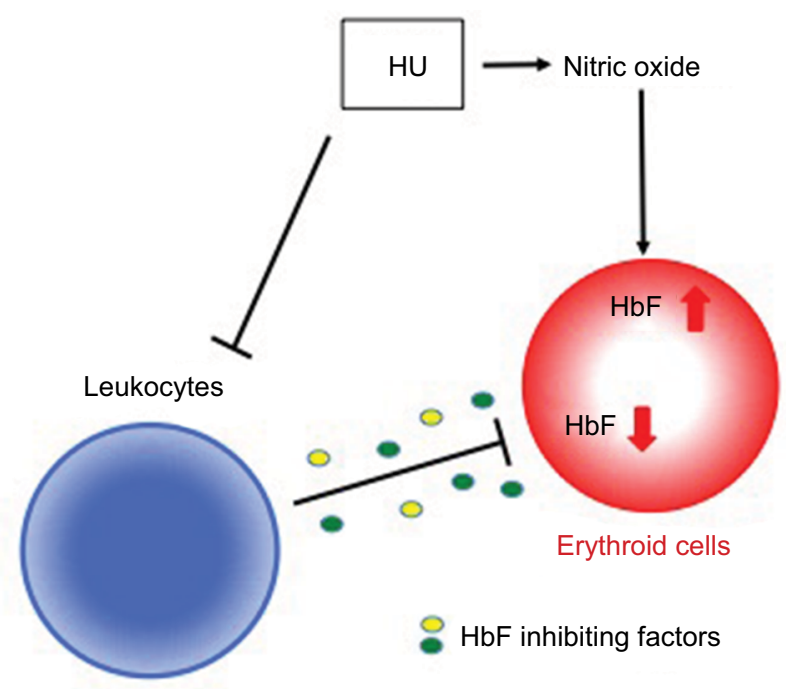

Figure 6 Possible model for the mechanisms that regulate $\mathrm{HU}$-induced $\mathrm{HbF}$ expression.

Notes: $\mathrm{HU}$ has been shown to stimulate HbF expression in erythroid cells through the nitric oxide/sGC/cGMP pathway. ${ }^{33-35} \mathrm{HU}$ is expected to suppress the proliferation of leukocytes by inhibiting ribonucleotide reductase, ${ }^{32}$ which in turn inhibits the production of $\mathrm{HbF}$ silencing factors.

Abbreviations: $\mathrm{HU}$, hydroxyurea; $\mathrm{HbF}$, fetal hemoglobin; sGC, soluble guanylate cyclase.

suggest that $\mathrm{HbF}$ expression is significantly influenced by the mechanisms controlling leukocyte count in the context of SCD.

The molecular and cellular mechanisms by which HUinduced $\mathrm{HbF}$ levels are associated with reduced leukocyte counts are not yet clear. Based on our study results, we hypothesize that leukocytes may secrete protein factors that bind to erythroid cells and inhibit HbF expression. Our in vitro studies (Figure 5) have demonstrated the presence of $\mathrm{HbF}$ silencing factors in the serum of SCD patients, whether or not they are receiving HU therapy. This is the first demonstration of $\mathrm{HbF}$ silencing factors in the serum of SCD patients. Interestingly, the $\mathrm{HbF}$ silencing activity in the serum varied significantly among SCD patients (Figure 5C, lanes 3 and 4). However, it can be argued that such factors may not in fact be secreted by leukocytes. Leukocyte numbers usually decrease in response to HU therapy in SCD because $\mathrm{HU}$ is a ribonucleotide reductase inhibitor. ${ }^{32}$ Consistent with this clinical evidence, $\mathrm{HbF}$ silencing activities are also concomitantly reduced in someone with SCD who is receiving $\mathrm{HU}$ (Figure 5C lane 5). Further rigorous scrutiny is required to verify that $\mathrm{HbF}$ silencing factors derive from leukocytes. Importantly, such $\mathrm{HbF}$ silencing factors were not absorbed by anti-GM-CSF antibody (Figure 5C), suggesting that $\mathrm{HbF}$ silencing factors are distinct from GM-CSF, which we showed has a negative consequence on $\mathrm{HbF}$ expression. ${ }^{17}$
Our current model of the role of leukocytes in HUmediated $\mathrm{HbF}$ expression in erythroid cells is summarized in Figure 6. We and others have shown that the soluble guanylate cyclase (sGC)-cGMP pathway plays a role in HU-induced $\mathrm{HbF}$ expression. ${ }^{33-35} \mathrm{HU}$ is assumed to augment $\mathrm{HbF}$ levels at least in part by generating nitric oxide and through the sGC-cGMP pathway. Although the sGC-cGMP pathway is also implicated in erythroid cells as a signaling mechanism for chemically induced $\mathrm{HbF}$ expression, it is still unknown whether extracellular signals from other lineage cells are transduced to erythroid cells and whether such signals are capable of modulating $\mathrm{HbF}$ expression by intracellular signaling pathways. In this study, we have clearly shown that $\mathrm{HbF}$ levels in SCD patients, whether they are receiving $\mathrm{HU}$ treatment, or not, are closely affected by leukocyte count in peripheral blood, presumably because of $\mathrm{HbF}$ silencing factors. As leukocyte count generally decreases in response to $\mathrm{HU}$ administration in SCD patients, it is reasonable to speculate that in addition to the nitric oxide/sGC-cGMP axis, $\mathrm{HU}$ might also increase $\mathrm{HbF}$ expression in SCD patients by inhibiting the secretion of $\mathrm{HbF}$ silencing factors from leukocytes. Collectively, there may be at least three groups of $\mathrm{HbF}$ regulatory proteins or pathways involved in $\mathrm{HbF}$ expression are possibly involved in inducing vaso-occlusive crisis therapy. One is GM-CSF, which is supposed to cause leukocytosis in $\mathrm{SCD}^{16}$ and has a negative consequence on $\mathrm{HbF}$ expression. ${ }^{17}$ Myeloid cytokines such as G-CSF or GMCSF are possibly involved to induce vaso-occlusive crisis. ${ }^{36,37}$ Second, $\mathrm{HU}$ is shown to stimulate $\mathrm{HbF}$ expression at least in part through the nitric oxide/sGC-cGMP axis. ${ }^{33-35}$ This is consistent with prior vitro and in vivo findings showing that nitric oxide is generated from HU. ${ }^{38,39}$ A third mechanism includes $\mathrm{HbF}$ silencing factors that are presumably released mainly from leukocytes, as reported in this study (Figure 5). $\mathrm{HbF}$ silencing factors may be cytokines or chemokines; further studies are necessary to precisely characterize $\mathrm{HbF}$ silencing factors.

\section{Conclusion}

This study has shown that HU-induced HbF expression is regulated at least in part by the mechanisms controlling leukocyte counts, and that $\mathrm{HbF}$ silencing factors that are secreted, possibly by leukocytes, may be involved in HU-regulated $\mathrm{HbF}$ expression in SCD. Thus, this study provides an important clue to the mechanisms by which $\mathrm{HbF}$ expression is regulated in the context of SCD patients receiving HU. It would be interesting to compare serum levels of cytokines or chemokines in SCD patients, both with and without HU 
treatment. Further insight into $\mathrm{HbF}$ silencing factors might help us clarify the mechanisms underlying $\mathrm{HU}$ resistance as seen in a subset of SCD patients. ${ }^{15,18}$

\section{Acknowledgments}

This study was supported in part by National Institutes of Health grants (DK61806, HL73452, and P20 MD003383 to TI) and the American Heart Association USA (15GRNT25710387 to TI). The funders had no role in study design, data collection and analysis, decision to publish, or preparation of the manuscript.

\section{Disclosure}

The authors report no conflicts of interest in this work.

\section{References}

1. Pauling L, Itano HA, Singer SJ, Wells IC. Sickle cell anemia a molecular disease. Science. 1949;110(2865):543-548.

2. Charache S, Barton FB, Moore RD, et al. Hydroxyurea and sickle cell anemia. Clinical utility of a myelosuppressive "switching" agent. The Multicenter Study of Hydroxyurea in Sickle Cell Anemia. Medicine (Baltimore). 1996;75(6):300-326.

3. Kaul DK, Hebbel RP. Hypoxia/reoxygenation causes inflammatory response in transgenic sickle mice but not in normal mice. J Clin Invest. 2000;106(3):411-420.

4. Reiter CD, Wang X, Tanus-Santos JE, et al. Cell-free hemoglobin limits nitric oxide bioavailability in sickle-cell disease. Nat Med. 2001;8(12):1383-1389.

5. Miller BA, Salameh M, Ahmed M, et al. High fetal hemoglobin production in sickle cell anemia in the eastern province of Saudi Arabia is genetically determined. Blood. 1986;67(5):1404-1410.

6. Craig JE, Rochette J, Fisher CA, et al. Dissecting the loci controlling fetal haemoglobin production on chromosomes $11 \mathrm{p}$ and $6 \mathrm{q}$ by the regressive approach. Nat Genet. 1996;12(1):58-64.

7. Close J, Game L, Clark B, Bergounioux J, Gerovassili A, Thein SL. Genome annotation of a $1.5 \mathrm{Mb}$ region of human chromosome $6 \mathrm{q} 23$ encompassing a quantitative trait locus for fetal hemoglobin expression in adults. BMC Genomics. 2004;5(1):33-46.

8. Yavarian M, Karimi M, Bakker E, Harteveld CL, Giordano PC. Response to hydroxyurea treatment in Iranian transfusion-dependent beta-thalassemia patients. Haematologica. 2004;89(10):1172-1178.

9. Lettre G, Sankaran VG, Bezerra MA, et al. DNA polymorphisms at the BCL11A, HBS1L-MYB, and beta-globin loci associate with fetal hemoglobin levels and pain crises in sickle cell disease. Proc Natl Acad Sci U S A. 2008;105(33):11869-11874.

10. Boggs DR, Hyde F, Srodes C. An unusual pattern of neutrophil kinetics in sickle cell anemia. Blood. 1973;41(1):59-65.

11. Platt OS, Brambilla DJ, Rosse WF, et al. Mortality in sickle cell disease. Life expectancy and risk factors for early death. $N$ Engl J Med. 1994;330(23):1639-1644.

12. Miller ST, Sleeper LA, Pegelow CH, et al. Prediction of adverse outcomes in children with sickle cell disease. N Engl J Med. 2000;342(2):83-89.

13. Brawley OW, Cornelius LJ, Edwards LR, et al. National Institutes of Health Consensus Development Conference Statement: hydroxyurea treatment for sickle cell disease. Ann Intern Med. 2008;148(12): 932-938.

14. Charache S, Dover GJ, Moore RD, et al. Hydroxyurea: effects on hemoglobin F production in patients with sickle cell anemia. Blood. 1992;79(10):2555-2565.
15. Ware RE, Eggleston B, Redding-Lallinger R, et al. Predictors of fetal hemoglobin response in children with sickle cell anemia receiving hydroxyurea therapy. Blood. 2002;99(1):10-14.

16. Conran N, Saad ST, Costa FF, Ikuta T. Leukocyte numbers correlate with plasma levels of granulocyte-macrophage colony-stimulating factor in sickle cell disease. Ann Hematol. 2007;86(4):255-261.

17. Ikuta $T$, Adekile AD, Gutsaeva DR, et al. The proinflammatory cytokine GM-CSF downregulates fetal hemoglobin expression by attenuating the cAMP-dependent pathway in sickle cell disease. Blood Cells Mol Dis. 2011;47(4):235-242.

18. Steinberg MH, Lu ZH, Barton FB, Terrin ML, Charache S, Dover GJ. Fetal hemoglobin in sickle cell anemia: determinants of response to hydroxyurea. Multicenter Study of Hydroxyurea. Blood. 1997;89(3):1078-1088.

19. Bailey L, Kuroyanagi Y, Franco-Penteado CF, et al. Expression of the gamma-globin gene is sustained by the cAMP-dependent pathway in beta-thalassaemia. Br J Haematol. 2007;138(3):382-395.

20. Kuroyanagi Y, Kaneko Y, Muta K, et al. cAMP differentially regulates gamma-globin gene expression in erythroleukemic cells and primary erythroblasts through c-Myb expression. Biochem Biophys Res Commun. 2006;344(3):1038-1047.

21. Ikuta T, Kan YW, Swerdlow PS, Faller DV, Perrine SP. Alterations in protein-DNA interactions in the gamma-globin gene promoter in response to butyrate therapy. Blood. 1998;92(8):2924-2933.

22. Suzuki Y, Takeda Y, Ikuta T. Immunoblotting conditions for human hemoglobin chains. Anal Biochem. 2008;378(2):218-220.

23. Ghoshal P, Rajendran M, Odo N, Ikuta T. Glycosylation inhibitors efficiently inhibit P-selectin-mediated cell adhesion to endothelial cells. PLoS One. 2014;9(6):e99363.

24. Lanzkron S, Strouse JJ, Wilson R, et al. Systematic review: hydroxyurea for the treatment of adults with sickle cell disease. Ann Intern Med. 2008;148(12):939-955.

25. Borba R, Lima CS, Grotto HZ. Reticulocyte parameters and hemoglobin F production in sickle cell disease patients undergoing hydroxyurea therapy. J Clin Lab Anal. 2003;17(2):66-72.

26. Lee SP, Ataga KI, Orringer EP, Phillips DR, Parise LV. Biologically active CD40 ligand is elevated in sickle cell anemia: potential role for platelet-mediated inflammation. Arterioscler Thromb Vasc Biol. 2006;26(7):1626-1631.

27. Uddin S, Ah-Kang J, Ulaszek J, Mahmud D, Wickrema A. Differentiation stage-specific activation of $\mathrm{p} 38$ mitogen-activated protein kinase isoforms in primary human erythroid cells. Proc Natl Acad Sci U SA. 2004;101(1):147-152.

28. Rodgers GP, Dover GJ, Noguchi CT, Schechter AN, Nienhuis AW. Hematologic responses of patients with sickle cell disease to treatment with hydroxyurea. N Engl J Med. 1990;322(15):1037-1045.

29. Ma Q, Wyszynski DF, Farrell JJ, et al. Fetal hemoglobin in sickle cell anemia: genetic determinants of response to hydroxyurea. Pharmacogenomics J. 2007;7(6):386-394.

30. Charache S, Dover GJ, Moyer MA, Moore JW. Hydroxyurea-induced augmentation of fetal hemoglobin production in patients with sickle cell anemia. Blood. 1987;69(1):109-116.

31. Steinberg MH. Management of sickle cell disease. $N$ Engl J Med. 1999;340(13):1021-1030.

32. Yarbro JW. Mechanism of action of hydroxyurea. Semin Oncol. 1992;19(3 Suppl 9):1-10.

33. Ikuta T, Ausenda S, Cappellini MD. Mechanism for fetal globin gene expression: role of the soluble guanylate cyclase-cGMP-dependent protein kinase pathway. Proc Natl Acad Sci U SA. 2001;98(4):1847-1852.

34. Cokic VP, Smith RD, Beleslin-Cokic BB, et al. Hydroxyurea induces fetal hemoglobin by the nitric oxide-dependent activation of soluble guanylyl cyclase. J Clin Invest. 2003;111(2):231-239.

35. Ikuta T, Cappellini MD. A novel mechanism for fetal globin gene expression: role of the soluble guanylate cyclase-cyclic GMP pathway [abstract]. Blood. 1999;94:615a.

36. Pieters RC, Rojer RA, Saleh AW, Saleh AE, Duits AJ. Molgramostim to treat SS-sickle cell leg ulcers. Lancet. 1995;345(8948):528. 
37. Abboud M, Laver J, Blau CA. Granulocytosis causing sickle-cell crisis. Lancet. 1998;351(9107):959.

38. Jiang J, Jordan SJ, Barr DP, Gunther MR, Maeda H, Mason RP. In vivo production of nitric oxide in rats after administration of hydroxyurea. Mol Pharmacol. 1997;52(6):1081-1086.
39. Glover RE, Ivy ED, Orringer EP, Maeda H, Mason RP. Detection of nitrosyl hemoglobin in venous blood in the treatment of sickle cell anemia with hydroxyurea. Mol Pharmacol. 1999;55(6):1006-1010.

\section{Publish your work in this journal}

The Journal of Blood Medicine is an international, peer-reviewed, open access, online journal publishing laboratory, experimental and clinical aspects of all aspect pertaining to blood based medicine including but not limited to: Transfusion Medicine; Blood collection, Donor issues, Transmittable diseases, and Blood banking logistics; Immunohematology; Artificial and alternative
Dovepress

blood based therapeutics; Hematology; Biotechnology/nanotechnology of blood related medicine; Legal aspects of blood medicine; Historical perspectives. The manuscript management system is completely online and includes a very quick and fair peer-review system. Visit http://www.dovepress.com/ testimonials.php to read real quotes from published authors. 